\title{
Mulheres, negritude e a construção de uma modernidade transnacional
}

\author{
Simone Pereira Schmidt (iD) 0000-0002-4650-5368 \\ Universidade Federal de Santa Catarina, Departamento de Língua e Literatura \\ Vernáculas, Programa de Pós-Graduação em Literatura/Programa de Pós-Graduação \\ Interdisciplinar em Ciências Humanas, Florianópolis, SC, Brasil. 88040-900 - \\ ppglitufsc@gmail.com
}

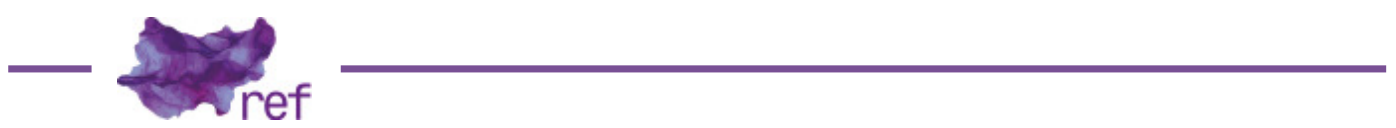

Resumo: Partindo do conceito de negritude formulado por Aimé Césaire, proponho uma reflexão sobre os desdobramentos da negritude em diferentes momentos históricos, nos quais o conceito é ressignificado através de interpretações que atendem às demandas políticas e culturais de cada contexto. Assim, meu texto pretende enfocar duas vozes poéticas femininas que, de maneiras diversas, fazem ecoar os princípios da negritude, reinterpretando-a à luz de suas agendas específicas: Noémia de Sousa, inserida no ambiente português e africano dos anos 50, e a cantora brasileira Luedji Luna, que retoma questões centrais do mesmo tema no contexto brasileiro pós-ações afirmativas. Através da abordagem dessas duas vozes, pretendo identificar redes transnacionais de construção de solidariedade planetária em perspectiva feminista e negra.

Palavras-chave: negritude; diáspora; poesia de autoria feminina; feminismo transnacional

Women, Negritude and the Construction of a Transnational Modernity

Abstract: Taking as a starting point the work of Aimé Césaire in his decisive formulation of the concept of négritude, I propose a reflection about this concept in different historical moments, answering to political and cultural demands of each context. Thus, this article intends to focus on two feminine poetic voices that, in different ways, echo the principles of négritude, reinterpreting it in its specific agendas: Noémia de Sousa inserted in the Portuguese and African environment of the 1950s, and the Brazilian Singer Luedji Luna, Who ressignifies central issues of the same theme in the Brazilian context after affirmative actions. Through the approach of these two voices of diasporic Black women, I intend to identify transnational networks of planetary solidarity construction in a feminist perspective.

Keywords: negritude; diaspora; poetry of female authorship; transnacional feminism

No cenário de efervescência cultural que mobilizou a Europa desde as primeiras décadas do século XX até o período do Pós-Guerra, um movimento de extrema relevância teve lugar, inscrevendose definitivamente na história; refiro-me ao movimento da negritude, especialmente em sua face mais radical, aquela formulada por Aimé CÉSAIRE, a partir da publicação de seu Caderno de um retorno ao país natal, em 1939. Data, aliás, de forte sentido simbólico, marcada pelo início dos conflitos da II Guerra Mundial. A obra de Césaire dialoga em justa medida com este momento, em que se evidencia a face desumana da civilização europeia, erigida sobre a violência colonial que então começava a se desnudar. Antônio Sérgio GUIMARÃES (2002), buscando investigar o processo de construção do que se pode considerar uma "modernidade negra", observa que o que se convencionou chamar 'modernidade' "foi fruto da obsolescência da ideia de civilização e tradição europeias, trazidas pelos horrores das guerras, principalmente das que, em 1914 e 1939, ganharam um caráter global" (GUIMARÃES, 2002, p. 2). Cabe lembrar as emblemáticas palavras de Jean-Paul SARTRE (1979), no prefácio a Os Condenados da terra, de Frantz Fanon:

Europeus, abri este livro, entrai nele [...] Encaremos primeiramente este inesperado: o strip-tease de nosso humanismo. Ei-lo inteiramente nu, e não é nada belo: não era senão uma ideologia 
mentirosa, a requintada justificação da pilhagem; sua ternura e seu preciosismo caucionavam nossas agressões (p. 8, 16-17).

A "modernidade negra" analisada por Antônio Sérgio Guimarães seria um processo construído através dos contatos, trocas e conflitos intensos entre negros e brancos, processo que se desenrola no tempo, e que é caracterizado pelo protagonismo assumido por diferentes personas que se definem a partir da palavra "negro": o escravo e o liberto, o diaspórico, o norte-americano, o latino-americano, o mestiço, o africano, o europeu do mundo ocidental pós-guerra. Cada uma dessas personas vai desenvolver uma relação específica e situada dentro da chamada modernidade negra, em interação, contato e conflito com o conceito de modernidade de sede europeia. Interessa, nesta proposição de uma ampla e transnacional modernidade negra, compreendê-la como um momento crucial da história ocidental, quando a negritude propõe que essas diferentes personas assumam o protagonismo de sua história e encarnem em seus discursos a tarefa de sua própria representação.

A contundência revolucionária da negritude consiste exatamente na força com que se reivindica a autoria, o protagonismo dos negros em formas de representação de sua experiência que eram, até então, proferidas e narradas pela voz altissonante dos europeus. Momento de explosão visionária, a negritude propõe um ideário, que por sua força de convocação, pelo apelo que lança à ideia de um porvir, em muito se aproxima do apelo das vanguardas que sacudiam a Europa, convulsionada pelas guerras e pelo desgastado retrato de si mesma que o processo histórico recente lhe mostrara. Foi em Cahier d'um retour au pays natal' que irrompeu pela primeira vez, como descreve Carlos MOORE (2010), "a palavra-noção, a palavra-missão, a palavra-doutrina, que se converteria em programa de combate e quase filosofia de emancipação; que definiria, para os negros do mundo inteiro, a própria práxis da busca identitária ao longo do século XX e na atualidade" (p. 18).

A partir do conceito da negritude como pedra fundamental para se pensar os movimentos de uma modernidade negra, pretendo escolher alguns momentos e algumas das personas que protagonizam esses momentos, enfocando especialmente vozes de mulheres. Essas vozes femininas, muitas vezes, construíram diálogos que de certo modo anteciparam o que hoje compreendemos como práticas transnacionais. Cruzando fronteiras geográficas e rompendo distâncias, elas criaram redes capazes de traduzir e colocar em contato experiências diversas do que significava - ou do que significa ainda hoje - ser mulher e negra. Através de diálogos, por vezes sutis, entre vozes de mulheres semelhantes mas diferentes, distantes mas tão próximas, se reinventa a paisagem afetiva dos espaços transnacionais, sinalizando para relações mais planetárias do que globais ou, em outras palavras, como argumenta Sandra Regina ALMEIDA (2011), com base em Gayatri Spivak, "enfatizando a alteridade e a humanidade do planeta em oposição à construção e artificialidade do globo" (p. 246). É ainda Sandra R. Almeida quem explica em mais detalhes a proposição desse redimensionamento do espaço geográfico, através de práticas feministas de contato transnacional, que em grande parte se aplica aos diálogos poéticos e políticos que aqui pretendo examinar:

A rigidez do globo, como sugerem Spivak, Gilroy e Brydon, se oporia à humanidade do planeta que, por sua vez, delineia a possibilidade de se pensar em cidadanias afetivas e em geografias emotivas nas quais o afeto e a emoção predominam como categorias de afiliação e ligação a outras possíveis geografias (ALMEIDA, 2011, p. 246).

A partir dessa motivação, escolho, portanto, algumas vozes poéticas de mulheres, oriundas de lugares e temporalidades distintas, para compor quadros, ensaiar algumas breves cenas do que considero os rastros desse gesto revolucionário de se pôr em contato, de dialogar com o outro, e, em especial, com a outra.

\section{Noémia de Sousa e os diálogos de uma poesia transnacional}

O potencial de construção de um canto paralelo de sobrevivência à dor e à morte, de resistência que anuncia um novo momento histórico, encontra-se elaborado na poesia de Noémia de Sousa, discurso que sintetiza toda a efervescência cultural e política de que fizeram parte a poetisa e tantos outros intelectuais africanos, que nos anos 50 do século XX davam partida, mormente a partir do exílio, para o espírito de liberdade que configuraria posteriormente a luta pela independência de seus países. É exemplar, nesse sentido, o poema "Deixa passar o meu povo" (Noémia de SOUSA, 2016, p. 48-50), ${ }^{2}$ que, em tom épico, celebra a chegada de uma consciência transnacional, em consonância com os caminhos que assumiria o tema da negritude no modernismo estético-político afro-americano.

\footnotetext{
' Obra do martinicano Aimé Césaire, publicada em 1939 na França. A edição brasileira, Diário de um retorno ao país natal, com tradução e estudos de Lilian Pestre de Almeida, foi publicada em 2012 pela EDUSP.

2 Todos os poemas de Noémia de Sousa aqui referenciados fazem parte do livro Sangue negro.
} 
Noite morna de Moçambique

e sons longínquos de marimbas chegam até mim

- certos e constantes -

vindos nem eu sei donde.

Em minha casa de madeira e zinco,

abro o rádio e deixo-me embalar...

Mas vozes da América remexem-me a alma e os nervos.

E Robeson e Marian cantam para mim

spirituals negros de Harlém.

"Let my people go"

- oh deixa passar o meu povo,

deixa passar o meu povo! -

dizem.

E eu abro os olhos e já não posso dormir.

Dentro de mim soam-me Anderson e Paul

e não são doces vozes de embalo.

"Let my people go!"

Nervosamente,

eu sento-me à mesa e escrevo...

Dentro de mim,

deixa passar o meu povo,

"oh let my people go..."

E já não sou mais que instrumento

do meu sangue em turbilhão

com Marian me ajudando

com sua voz profunda - minha irmã!

Escrevo...

Na minha mesa, vultos familiares se vêm debruçar.

Minha Mãe de mãos rudes e rosto cansado

e revoltas, dores, humilhações,

tatuando de negro o virgem papel branco.

E Paulo, que não conheço,

mas é do mesmo sangue e da mesma seiva amada de Moçambique,

e misérias, janelas gradeadas, adeuses de magaíças,

algodoais, o meu inesquecível companheiro branco,

e Zé - meu irmão - e Saúl,

e tu, Amigo de doce olhar azul,

pegando na minha mão e me obrigando a escrever

com o fel que me vem da revolta.

Todos se vêm debruçar sobre o meu ombro,

enquanto escrevo, noite adiante,

com Marian e Robeson vigiando pelo olho luminoso do rádio

- "let my people go

oh let my people go!"

E enquanto me vierem de Harlém

vozes de lamentação

e meus vultos familiares me visitarem

em longas noites de insónia,

não poderei deixar-me embalar pela música fútil

das valsas de Strauss.

Escreverei, escreverei,

com Robeson e Marian gritando comigo: 
Let my people go,

OH DEIXA PASSAR O MEU POVO!

Neste poema, a música está presente desempenhando o papel fundamental de elo de ligação entre as diferentes margens do Atlântico Negro. ${ }^{3} \mathrm{O}$ eu poético escuta, na morna noite de Moçambique, o chamado de seus irmãos norte-afro-americanos que, entoando um spiritual originário do sul dos Estados Unidos, evocam o sofrimento do povo eleito na Bíblia, em seu momento crucial de fuga do cativeiro no Egito, tal como está relatado no Êxodo. "Let my people go", diz o refrão, ecoando nas paredes do Harlem e na "casa de madeira e zinco" em Moçambique. Nesta mesma casa se fundem os "sons longínquos de marimba", vindos não se sabe de onde, talvez da rua em frente, talvez de um passado mítico onde jazem os ancestrais, e a canção no rádio, marca de modernidade, que traz as "vozes da América" para remexer alma e nervos do eu poético.

O spiritual, que chega à casa em Moçambique através das poderosas vozes de Paul Robeson e Marian Anderson, é um ícone fundamental da geração de artistas negros, que, a partir do Harlem, e especialmente nos anos 1930, deu corpo a uma intensa produção artística e cultural que ficou conhecida como a Black Renaissance. Música, artes plásticas, literatura, constituíram discursos onde se construiu este novo sujeito negro, fruto de um momento político para o qual confluíram as experiências dos intelectuais negros das Américas, do Caribe e da África. O the new negro movement agregava essas experiências diaspóricas, constituindo, através de seus discursos estéticos e políticos, "um espaço de forte identificação" (Maria Manuela Jales Camposana de ARAÚJO, 2008, p. 152) com base na história compartilhada da escravidão e da "sua total exclusão da sociedade política moderna" (Paul GILROY, 2001, p. 164).

No cerne desse processo de identificação encontrava-se a experiência do enfrentamento das desigualdades sociais e raciais. Por isso, a poetisa diz: "Dentro de mim soam-me Anderson e Paul / e não são doces vozes de embalo". Longe de ser acalentada pelo doloroso canto dos músicos afro-americanos, o sujeito poético sente-se provocado por eles, a, "nervosamente", sentarse à mesa, e escrever.

É a experiência histórica compartilhada, o ponto de ancoragem a partir do qual o sujeito poético, ouvindo as vozes de seus irmãos afro-americanos, Marian e Robeson, apercebe-se da necessidade de rejeitar os modelos impostos pelo colonialismo:

E enquanto me vierem de Harlem
vozes de lamentação
e os meus vultos familiares me visitarem
em longas noites de insónia,
não poderei deixar-me embalar pela música fútil
das valsas de Strauss.

Os versos sinalizam para a construção de uma outra história, uma história de resistência e recusa das "premissas estéticas etnocêntricas da modernidade" (GILROY, 2001, p. 164), formulando os esboços daquilo que Walter MIGNOLO (2003) viria a chamar um "paradigma outro", ou seja, "o pensamento de um sujeito que não quer que lhe dêem a liberdade, mas que quer tomá-la por si mesmo, construindo seu próprio projeto num paradigma outro, e não [se] deixar atar ao paradigma da modernidade" (p. 31), esgotado em seu potencial desigual de liberação.

Contagiado pelas vozes que vêm do Harlem, e que o vigiam "pelo olho luminoso do rádio", o sujeito poético toma impulso para se debruçar à mesa, e, acompanhado por seus vultos tutelares, cumprir o ofício da escrita:

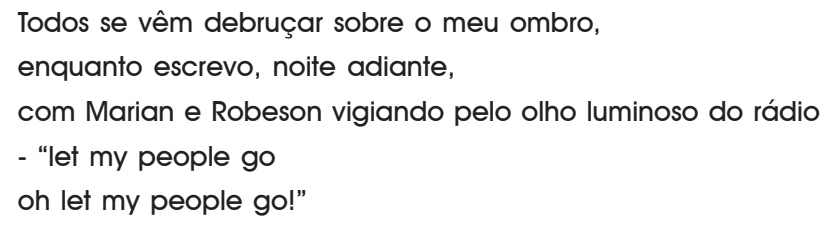

Neste momento a distância entre Moçambique e a América se apaga. De seu exílio simbólico de sujeito colonizado, sozinha na noite morna de seu país, a poetisa escreve, e sua escrita é um discurso em contraponto, no sentido atribuído por Edward SAID (2003) à experiência contrapontística do exilado, que tem o poder de estar em dois lugares ao mesmo tempo, por meio de uma "consciência de dimensões simultâneas" (p. 53). Assim, o mundo dolorosamente cindido do sujeito

${ }^{3}$ Expressão cunhada por Paul Gilroy, em sua conhecida obra O Atlântico negro: modernidade e dupla consciência (Rio de Janeiro: Universidade Cândido Mendes, Centro de Estudos Afro-Asiáticos, 2001), referindo-se aos trânsitos culturais atlânticos advindos da escravidão. 
colonizado, tal como diagnosticou Frantz FANON (1979, p. 27-32), se converte, pela música e pela poesia, numa experiência estética libertadora em contraponto: lá e cá, vozes de lamento e revolta se erguem para exclamar "let my people go", "deixa passar o meu povo".

Dentro da mesma ambiência do movimento cultural modernista afro-americano, em "A Billie Holiday, cantora" (SOUSA, 2016, p. 123-124), Noémia de Sousa estabelece outro elo, ainda mais íntimo e profundo, desta vez com outra irmã afro-americana, cuja voz sintetiza todos os lamentos dos ex-escravizados:

Era de noite e no quarto aprisionado em escuridão apenas o luar entrara, sorrateiramente,

e fora derramar-se no chão.

Solidão. Solidão. Solidão.

E então,

tua voz, minha irmã americana,

veio do ar, do nada nascida da própria escuridão...

Estranha, profunda, quente,

vazada em solidão.

E começava assim a canção:

"Into each heart some rain must fall..."

Começava assim

e era só melancolia

do princípio ao fim,

como se teus dias fossem sem sol

e a tua alma aí, sem alegria...

Tua voz irmã, no seu trágico sentimentalismo,

descendo e subindo,

chorando para logo, ainda trémula, começar rindo,

cantando no teu arrastado inglês crioulo

esses singulares "blues", dum fatalismo

rácico que faz doer

tua voz, não sei por que estranha magia,

arrastou para longe a minha solidão...

No quarto às escuras, eu já não estava só!

Com a tua voz, irmã americana, veio

todo o meu povo escravizado sem dó

por esse mundo fora, vivendo no medo, no receio

de tudo e de todos...

O meu povo ajudando a erguer impérios

e a ser excluído na vitória...

A viver, segregado, uma vida inglória,

de proscrito, de criminoso...

O meu povo transportando para a música, para a poesia,

os seus complexos, a sua tristeza inata, a sua insatisfação...

Billie Holiday, minha irmã americana,

continua cantando sempre, no teu jeito magoado

os "blues" eternos do nosso povo desgraçado...

Continua cantando, cantando, sempre cantando,

até que a humanidade egoísta ouça em ti a nossa voz,

e se volte enfim para nós,

mas com olhos de fraternidade e compreensão! 
Na dor compartilhada entre as duas mulheres, na escuridão do quarto escuro subitamente povoado pela voz "estranha, profunda, quente, / vazada em solidão" da cantora negra americana, podemos encontrar mais do que o "fatalismo rácico que faz doer" anunciado pelo eu poético. Podemos mesmo entrever a difícil conjunção de raça e gênero na trajetória dessas singulares e solitárias mulheres num cenário cultural e político onde a dor da condição dos negros ainda não oferecia espaço para que as particularidades da experiência das mulheres negras fossem percebidas e valoradas.

Vale lembrar que, como afirmaram Maylei BLACKWELL e Nadine NABER (2002, p. 191-192), embora as mulheres tenham sido historicamente o grupo mais vulnerável no contexto das formas do colonialismo e de escravidão, ainda assim permaneceram à margem nas políticas masculinistas de liberação nacional e nas lutas comunitárias contra o racismo.

Dessa concepção, tão frequente no imaginário anticolonial, se pode depreender um impasse colocado às mulheres: por um lado, o compartilhamento da luta e o forte pertencimento ao movimento cultural, político, de luta pela transformação das relações étnico-raciais; por outro, a solidão das mulheres nesta luta, e o sentimento de exclusão em momentos decisivos de elaboração identitária, estética e política da negritude.

Portanto, não é incidental a solidão insistentemente repetida pela voz poética nos versos:

Era de noite e no quarto aprisionado em escuridão

apenas o luar entrara, sorrateiramente,

e fora derramar-se no chão.

Solidão. Solidão. Solidão.

Solidão que só se resolve com a entrada em cena do "arrastado inglês crioulo", na voz melancólica da irmã americana que, com seus blues, cantou a dor de todos os negros, mas, acima de tudo, cantou a melancolia, a grande dificuldade de ser uma mulher negra em seu tempo e lugar.

Podemos, portanto, pensar na música, tal como propôs Paul Gilroy, como eixo aglutinador tanto da memória traumática dos "terrores inefáveis da escravidão" (GILROY, 2001, p. 158) quanto da experiência vibrante de construção das novas identidades negras nos movimentos culturais e políticos da negritude, da black renaissance norte-americana, seguidos pelos movimentos de libertação na África. Noémia de Sousa percebeu como poucos o alcance e a profundidade do diálogo que então se começava a estabelecer neste que ficou conhecido como o espaço simbólico do Atlântico Negro.

Contudo, dentro dos discursos que anunciavam a unidade de povos dispersos pela diáspora africana no mundo, algumas vozes femininas, ainda solitárias e melancólicas, mas desde então poderosas, levantavam-se para enunciar uma outra música, sonoramente mais polifônica, e perceptivelmente contrapontística, onde os tons da diferença de gênero, para além da igualdade de raça, precisavam ser ouvidos.

\section{O Brasil pós-ações afirmativas: acertando as contas com o passado}

É a música que de novo nos transporta, de um continente ao outro, atravessando espaço e tempo, em direção ao Brasil de agora. A negritude, conceito expandido e muitas vezes mal interpretado, ganha novos significados no contexto brasileiro pós-elogio da mestiçagem. Ao analisar as diferentes "modernidades negras" que se podem identificar na história do século XX, Antônio Sérgio Guimarães observa a lenta transição, no Brasil, de uma modernidade construída a partir do ideal da nação mestiça (cujos pressupostos foram propagados a partir de Gilberto Freyre) até a emergência, a partir dos anos 70 e 80 , de um pensamento negro menos voltado para o projeto nacional e de perfil mais transnacional, em diálogo com os movimentos negros de outros continentes e particularmente interessado em suas origens africanas.

Fruto deste novo momento, o Brasil 'pós-ações afirmativas' chega ao século XXI mais negro, por um lado, e, por outro, mais consciente acerca do seu próprio racismo. Como afirmou Boaventura de Sousa SANTOS (2006), a implementação dessa política de reparação aos direitos usurpados à população negra brasileira promoveu, finalmente, a passagem do país do período pósindependência para o período pós-colonial. Pois, como disse Fábio Konder COMPARATO (2008),

em 13 de maio de 1888, abolimos a escravidão tal como encerramos, quase um século depois, os horrores do regime militar: viramos simplesmente a página. Os senhores de escravos e seus descendentes não se sentiram minimamente responsáveis pelas conseqüências do crime nefando praticado durante quase quatro séculos.

A cantora e compositora Luedji LUNA (2017), baiana radicada em São Paulo, representa em suas canções e performances a determinação em assumir a negritude como projeto amplo e 
transnacional, voltado simultaneamente para dentro (as questões urbanas, os imigrantes) e para fora (as rotas da diáspora, o passado das travessias atlânticas, a memória das viagens, das trocas culturais e da escravidão). Os ideais nacionalistas, o projeto da mestiçagem, estão definitivamente fora de cena.

Na canção "Um corpo no mundo", a compositora se propõe a "olhar a si na interação com os imigrantes africanos que moram em São Paulo". Como podemos ler na sinopse de seu álbum, "um corpo no mundo remete a travessia e deslocamento". ${ }^{4}$ É assim, falando de corpo e de não pertencimento, de travessias e memórias, que encontramos em Luedji Luna o cenário que sintetiza o Brasil urbano contemporâneo. O corpo no mundo, à solta pela cidade, canta a solidão da diáspora.

A canção ${ }^{5}$ inicia com versos que situam o sujeito lírico no espaço simbólico do Atlântico Negro, conceito criado por Paul Gilroy para nomear a transcultura negra, oriunda das rotas atlânticas iniciadas a partir da escravidão, as quais resultaram em "culturas planetárias mais fluidas e menos fixas" (GILROY, 2001, p. 15).

\author{
Atravessei o mar \\ Um sol da América do Sul me guia \\ Trago uma mala de mão \\ Dentro uma oração \\ Um adeus...
}

A mala de mão nos remete a partidas e rupturas, mas o sujeito tem por guias um sol e uma oração, o sol presente na América e a oração que remete ao passado. A referência à América do Sul amplia sua localização: o sujeito não está apenas em São Paulo, ou no Brasil, está na América do Sul, o continente que vê como estrangeira mas do qual se aproxima, e para o qual enuncia, talvez, uma identidade que não percebemos com clareza. Autoras precursoras da discussão sobre a negritude no Brasil, como Lélia Gonzalez, já identificavam, desde os anos 80 , a necessidade de se considerar as reivindicações e experiências históricas comuns de povos ameríndios e africanos, reportando-se a uma América menos "Iatina", uma "Améfrica Ladina" (apud Cláudia Pons CARDOSO, 2014, p. 970), como propunha a autora, antecipando em algumas décadas o que hoje se discute amplamente nos debates sobre o descolonial na América.

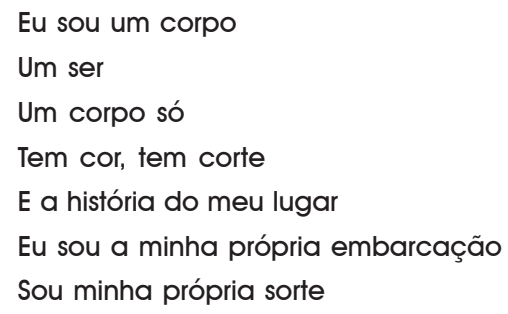

Ao enunciar "eu sou um corpo", o sujeito define um elemento-chave de sua identidade. Um corpo só - solitário, solto, e também 'só' um corpo, e mais nada. Corpo que muitas vezes foi o único capital cultural das populações negras do mundo, segundo Stuart HALL (2003), e a traduzir, em seus movimentos, "as relações complexas entre as origens africanas e as dispersões irreversíveis da diáspora" (p. 342-343), como assinala o autor jamaicano.

Neste "corpo só" ecoa o passado ("tem cor, tem corte, e a história do meu lugar"), mas também a voz de muitos outros e outras personas da negritude, como o canto de Nina SIMONE (1968), que nos emblemáticos anos 60, afirmava repetidamente, na canção "Ain't got no, I got life", o seu radical não pertencimento e a sua condição de absoluta exclusão do modo de vida ocidental burguês:

Ain't got no home, ain't got no shoes Ain't got no money, ain't got no class Ain't got no skirts, ain't got no sweaters Ain't got no perfume, ain't got no love Ain't got no Faith

$$
[\ldots]
$$

\footnotetext{
${ }^{4}$ Trechos da sinopse sobre o álbum "Um corpo no mundo", de Luedji Luna. Disponível em https://www.catarse.me/ umcorponomundo luedjiluna. Acesso em 15/06/2018.

5 "Um corpo no mundo", canção e performance de Luedji Luna. Disponível em https://www.youtube.com/watch?v=VG7LC6QzTA. Acesso em 15/06/2018.
} 


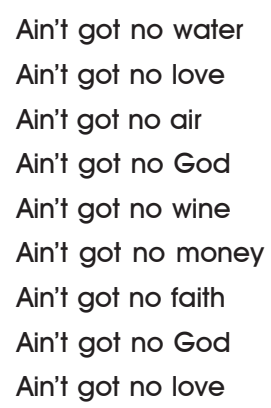

E ao se perguntar em seguida, na canção, "Then what have I got/ Why am I alive anyway?", é em seu próprio corpo - seu corpo só, e nada mais - que a grande compositora afro-americana encontra todas, todas as suas respostas:

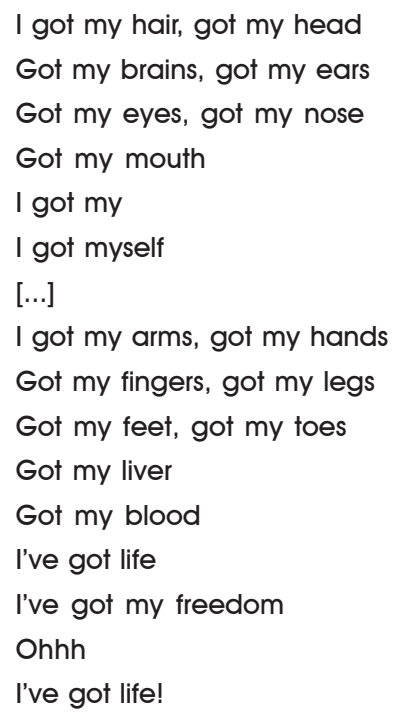

Este é, portanto, um corpo que viaja e atravessa as fronteiras de uma consciência de si, que se constrói na negritude e se transforma em arma para enfrentar os "olhares brancos que me fitam", o "perigo nas esquinas", a solidão e o estranhamento.

\author{
Cada rua dessa cidade cinza sou eu \\ Olhares brancos me fitam \\ Há perigo nas esquinas \\ E eu falo mais de três línguas
}

E esse sujeito que "fala mais de três línguas", porque pertence a muitos lugares e carrega uma história feita de trânsitos atlânticos, esse sujeito que representa perigo para os olhares da cidade e enfrenta o perigo real das esquinas, enuncia sua condição de imigrante, de estar aqui, desafiando distâncias e barreiras:

E Je suis ici, ainda que não queiram não

Je suis ici, ainda que eu não queira mais

Je suis ici agora

O sujeito cosmopolita que fala mais de três línguas, e que afirma em francês o seu "estar aqui" não encontra, contudo, nas línguas que exercita em seu esforço de compreensão recíproca em terra estrangeira, algo que possa definir como a palavra "amor". Seu corpo negro, vestido de branco segundo as tradições ancestrais que carrega consigo, movimenta-se e dança nas ruas povoadas da cidade cinza, e seu gesto atravessa o mar em direção ao mesmo lamento que povoa o canto de Noémia de Sousa para Billie Holiday: Solidão. Solidão. Solidão.

E a palavra amor, cadê?

Je suis ici, ainda que não queiram não 


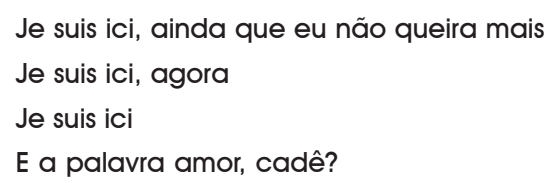

Vemos assim essa teia desdobrada de vozes de mulheres na diáspora, corpos no mundo, corpos sós, em busca de outras vozes onde ecoem suas próprias vivências. Os gestos e palavras de Noémia de Sousa, Billie Holiday, Nina Simone, Lélia Gonzales, Luedji Luna se desdobram, numa poética de negritude em "vozes-mulheres" que inscrevem no tempo e no espaço, como disse Conceição Evaristo, "o ontem - o hoje - o agora". 6

\section{Referências}

ALMEIDA, Sandra Regina. "Exílios e diásporas: cartografias de gênero na contemporaneidade". In: RIAL, Carmen et al. (org.). Diásporas, mobilidades e migrações. Florianópolis: Mulheres, 201 1. p. 239-256.

ARAÚJO, Maria Manuela Jales Camposana de. Textos afro-americanos e textos africanos: discursos do Eu ao espelho repartido da diáspora discursiva moderna. 2008. Tese (Doutorado em Letras) - Faculdade de Letras, Literatura Norte-Americana, Universidade de Lisboa, Lisboa.

BLACKWELL, Maylei; NABER, Nadine. "Interseccionalidade em uma era de globalização: as implicações da Conferência Mundial contra o Racismo para práticas feministas transnacionais". Revista Estudos Feministas, v. 10, n. 1, p. 189-198, $1^{\circ}$ sem. 2002.

CARDOSO, Cláudia Pons. "Amefricanizando o feminismo: o pensamento de Lélia Gonzalez". Revista Estudos Feministas, Florianópolis, v. 22, n. 3, p. 965-986, set./dez. 2014.

COMPARATO, Fábio Konder. "Um débito colossal". Folha de S. Paulo, São Paulo, 09/07/2008. Disponível em http://wwwl folha.uol.com.br/fsp/opiniao/fz0807200808.htm. Acesso em 10/09/2008.

FANON, Frantz. Os condenados da terra. 2.ed. Rio de Janeiro: Civilização Brasileira, 1979.

GILROY, Paul. O Atlântico negro: modernidade e dupla consciência. São Paulo: Ed. 34; Rio de Janeiro: Universidade Cândido Mendes, Centro de Estudos Afro-Asiáticos, 2001.

GUIMARÃES, Antônio Sérgio A. "A modernidade negra no Brasil, EUA e França". ENCONTRO DA ANPOCS, Caxambu, out. 2002. Disponível em http://www.anpocs.com/index.php/papers-26encontro/gt-23/gt23-16/4507-aguimaraes-a-modernidade/file. Acesso em 12/05/2017.

HALL, Stuart. "Que 'negro' é esse na cultura negra?". In: HALL, Stuart. Da diáspora: identidades e mediações culturais. Belo Horizonte: EDUFMG; Brasília: Representação da UNESCO no Brasil, 2003. p. 335-349.

LUNA, Luedji. Um corpo no mundo. Gravadora YB Music, 27/10/2017.

MIGNOLO, Walter. Histórias locais, projetos globais: colonialidade, saberes subalternos e pensamento liminar. Belo Horizonte: EDUFMG, 2003.

MOORE, Carlos. “'Negro sou, negro ficarei!' A negritude segundo Aimé Césaire”. In: CÉSAIRE, Aimé. Discurso sobre a negritude. Belo Horizonte: Nandyala, 2010. p. 9-40.

SAID, Edward. Reflexões sobre o exílio e outros ensaios. São Paulo: Companhia das Letras, 2003.

SANTOS, Boaventura de Sousa. "As dores do pós-colonialismo". Folha de S. Paulo, São Paulo, 11/08/ 2006.

SARTRE, Jean-Paul. "Prefácio". In: FANON, Frantz. Os condenados da Terra. 2.ed. Rio de Janeiro: Civilização Brasileira, 1979. p. 1-21.

SIMONE, Nina. "Ain't got no/ I got life". In: SIMONE, Nina. 'Nuff Said!, 1968. New York: RCA Studios. Disponível em https://www.letras.mus.br/nina-simone/36305/. Acesso em 15/06/201 8.

SOUSA, Noémia de. Sangue negro. São Paulo: Kapulana, 2016.

6 "Vozes-mulheres", poema de Conceição Evaristo. Disponível em http://www.educacaopublica.rj.gov.br/cultura/ prosaepoesia/0151.html. Acesso em 15/06/2018. 
Simone Pereira Schmidt (simonepschmidt@gmail.com) é doutora em Teoria Literária pela Pontifícia Universidade Católica do Rio Grande do Sul, realizou Pós-Doutoramento em Literaturas de Língua Portuguesa na Universidade Nova de Lisboa (2005) e em Literaturas Africanas de Língua Portuguesa na UFF (2012). É Professora Associada da UFSC, exerce docência e orientação no Curso de Letras-Português e no Programa de Pós-Graduação em Literaturas da UFSC. É pesquisadora do CNPq vinculada ao Literatual/UFSC (Núcleo de Pesquisa em Literatura Atual-Estudos Feministas e Pós-Coloniais de Narrativas da Contemporaneidade), ao IEG/UFSC (Instituto de Estudos de Gênero), ao GT "A Mulher na Literatura", da ANPOLL, e ao Grupo de Pesquisa "África, Brasil, Portugal; interlocuções literárias" (UFF-CNPq). Atua nas áreas de estudos feministas e pós-coloniais, desenvolvendo pesquisa sobre "Escritoras africanas e a construção de um pensamento ao Sul".

\section{COMO CITAR ESSE ARTIGO DE ACORDO COM AS NORMAS DA REVISTA}

SCHMIDT, Simone. "Mulheres, negritude e a construção de uma modernidade transnacional". Revista Estudos Feministas, Florianópolis, v. 27, n. 1, e58957, 2019.

\section{CONTRIBUIÇÃO DE AUTORIA}

Concepção, análise de obras, redação e finalização.

\section{FINANCIAMENTO}

CNPq (bolsa de produtividade em pesquisa)

CONSENTIMENTO DE USO DE IMAGEM

Não se aplica

APROVAÇÃO DE COMITÊ DE ÉTICA EM PESQUISA

Não se aplica

CONFLITO DE INTERESSES

Não se aplica

LICENÇA DE USO

Este artigo está licenciado sob a Licença Creative Commons CC-BY. Com essa licença você pode compartilhar, adaptar, criar para qualquer fim, desde que atribua a autoria da obra.

\section{HISTÓRICO}

Recebido em 01/09/2018

Aprovado em 07/09/2018 